\title{
The Relationship between Language and Thought in \\ Motion Event Cognition in Second Language \\ Acquisition
}

Soo-Ok Kweon ${ }^{\dagger}$

POSTECH

\begin{abstract}
This study aims to investigate the relationship between language and thought in motion events encoding (linguistic perspective) and the perception (non-linguistic perspective) of Korean learners of English. The purpose is to determine whether L2 learners will shift toward L2-based conceptual representations when they can switch the linguistic behavior of encoding motion from their L1 (Korean) to L2 (English). A verbal description task to test linguistic switch and a similarity rating task to test conceptual change are used with animations that describe motion events. Results show that although the linguistic switch to the L2 canonical type of description occurs, the switch does not result in cognitive restructuring by L2 learners when language is not involved. The results will be discussed with respect to "thinking for speaking" and the linguistic relativity dubbed the Sapir-Whorf hypothesis.
\end{abstract}

Keywords: motion events, L2 acquisition, thinking for speaking, linguistic relativity, language and thought

\section{Introduction}

One of the persistent questions in second language (L2) acquisition is that if L2 learners can speak as fluently in L2 as in L1, would it be possible for them to make conceptual shifts in how they think about events in the world; i.e., does learning an additional language in adulthood affect the L2 learners' conceptual representation?

This question of language and conceptualization examines whether language can shape the way people think even if they do not think for speaking. The culmination of this question on the interaction of language and thought was the Sapir-Whorf Hypothesis ([1940] 2012) based on linguistic determinism. The strong version of the

\footnotetext{
* This work was supported by the Ministry of Education of the Republic of Korea and the National Research Foundation of Korea (NRF-2017S1A5A2A01026703).

† Corresponding author: soook@postech.ac.kr
} 
Sapir-Whorf Hypothesis holds that "differences among languages cause differences in the thoughts of their speakers" (p. 65). The linguistic deterministic idea of this hypothesis is that language can determine the way in which people think, even if they do not use language in the thoughts. This strong version of Sapir-Whorf Hypothesis implies implicitly that people think in language-specific ways, even when they are not actively using language during non-linguistic cognitive processing (Brown \& Lenneberg,1954; Lucy, 1992). This version of the Sapir-Whorf Hypothesis is overly deterministic and is not supported by evidence (Swoyer, 2011).

Another view is what we will call the weak version of Sapir-Whorf Hypothesis. Thinking for speaking (Slobin, 1996; 2000; 2004) account is a modified weak version of the Sapir-Whorf Hypothesis. Thinking for speaking is based on linguistic relativity, which emphasizes the influence of language on conceptual representation only during the processing of speaking (i.e., 'intimately tied to language', Slobin, 1996, p. 75). Thinking for speaking does not concern the influence of language on non-linguistic cognition in general (see Bassetti \& Cook, 2011 for discussion). Slobin's proposal is different from the linguistic determinism (i.e., strong Sapir-Whorf Hypothesis) claim in that Slobin specifies how thought is to be shaped by languagespecific patterns during online language processing, whereas the linguistic determinism proposal allows thoughts to be invariably influenced by language, whether one is speaking or not (Lai, Rodriguez, \& Narasimhan, 2014).

Many studies have examined the relationship between language and conceptualization focusing on motion events mainly, first, in L1 acquisition research done in linguistic condition observing children learning their native language (Allen, Ozyrek, Kita, Brown, Furman, Ishizuka \& Fujii, 2007; Choi \& Bowerman, 1991; Gentner, 2003; Goldin-Meadow \& Zheng, 1998; Maguire \& Dove, 2008). Second, L1 psycholinguistic research involving verbal productions of L1 speakers (Allen et al., 2007; Athanasopoulos \& Bylund, 2013; Berman \& Slobin, 1994; Bylund, 2009, Bylund \& Athanasopoulos, 2014; Choi \& Bowerman,1991; Oh, 2003; Slobin, 1996; 2000, among others). Third, L2 psycholinguistic research involving verbal production by L2 learners (Brown \& Gullberg, 2013; Cadierno \& Ruiz, 2006; Choi \& Lantolf, 2008; Hendriks \& Hickmann, 2011; Hohenstein, 2006; Lai et al., 2014, among many).

To widen the understanding of the influence of language on thought, the behavior patterns of language users must be investigated not only in linguistic condition, but in non-linguistic condition that does not involve use of language. However, this type of study has been relatively scarce in L1 research (cf. Papafragou, Hulbert, \& Trueswell, 2008; Trueswell \& Papafragou, 2010) and almost absent in L2 research 
(cf. Czechowska \& Ewert, 2011). None of the published research to date has tested the switch to L2 in speaking (linguistic) and conceptual restructuring (non-linguistic) together by adult L2 learners, focusing on motion events.

This study attempts to fill the gap by investigating the relationship between language and conceptualization in the setting of L2 acquisition and processing of motion events, from both a linguistic perspective (verbal description) and from a non-linguistic perspective (perception). More specifically, the idea is to determine, if linguistic switch occurs in encoding motion events by Korean adult learners of L2 English, whether the linguistic switch can cause them to also experience conceptual changes in perceiving the motion events accordingly. The possibility of conceptual changes in L2 cannot be examined by looking only at language production in the absence of non-linguistic performance.

\section{Theoretical Background}

\subsection{Motion events}

Human languages vary in how they encode descriptions of motion events. The way people perceive motion events is influenced by the languages they know and use. Languages can be classified into two broad categories that use different ways to encode lexicalization patterns of semantic components of a motion event (Talmy, 1985; 2000). A motion event is defined as a change of location, so the key information about the motion event is its PATH (Talmy, 1985). According to Talmy's (1985; 2000) typology of languages, languages can be divided into two groups that differ in how they encode the PATH of motion, i.e., trajectory or the directionality of the moving object. Satellite-framed languages, including English, German and Chinese, represent PATH by satellites to the verb such as particles or prepositional phrases (to the house) and convey MANNER as a main verb (ran) as in (1).

(1) English: He ran into the house.

Verb-framed languages, including Spanish, Turkish and Korean, indicate PATH by the main verb in a clause: verbs such as entar 'enter', salir 'exit', and MANNER of motion are expressed in independent constituents or as adverbial phrases (running) as in (2). 
(2) Spanish: Entró a la casa corriendo.

'He entered the house running'

The preferred pattern in such languages is to use the main verb to encode either "simple motion (e.g., 'go') or directed motion (e.g., 'enter'), then to express MANNER in an optional adjunct phrase, in those instances, when MANNER is at issue." (Slobin, 2000, p. 110).

Korean is a Verb-framed language; it uses verbs to expresses most PATH information, and uses adverbs to express MANNER separately. In sentence (3), the main verb in motion clause is a serial verb that is composed of the verb tul 'enter' and a deitic verb (i.e., kata 'go'). This serial main verb indicates motion PATH, i.e., the core schema of a motion event. The MANNER of motion is encoded by the optional verb ttwui 'run.

(3) namca-ka dongkul-lo (ttwui-e) tul-e ka-ss-ta.

Man-SUBJ cave-LOC (run-CONN) enter-CONN go-PST-DECL [FIGURE] [GROUND] $\quad([\mathrm{MANNER}])$ [PATH] $\quad$ [DEIXIS]

'A man went in(to) the cave (running).'

Satellite-framed languages differ systematically from Verb-framed languages in how they express motion and the concept related to it. Languages such as English have verbs that conflate motion and MANNER, whereas languages such as Korean have verbs that conflate motion and PATH. Therefore, Satellite-framed languages (e.g., English) are MANNER-oriented languages, whereas Verb-framed languages (e.g., Korean) are PATH-oriented languages.

\subsection{Research on linguistic description of motion in L1}

Numerous studies have examined how Talmy's (1985, 2000) typological framework and Slobin's (1996) thinking for speaking hypothesis affect the expression of motion by native speakers of various languages. At the most general level, native speakers of different languages have shown different motion event categorization patterns with language-specific lexical pressure on event components (i.e., MANNER encoding or PATH encoding of motion events). Thinking for speaking while comprehending motion events has been investigated with speakers of MANNER-oriented and PATH-oriented languages in different verbal production tasks in which they were 
asked to describe events depicted as static pictures, animations or videos. Crucially, speakers of MANNER-oriented languages (i.e., English) preferred MANNER verbs, whereas speakers of PATH-oriented languages (i.e., Spanish) preferred PATH verbs.

For instance, Papafragou and Selimis (2010) examined English- and Greek-speaking adults and five-year-old children and found that English speakers preferred to use MANNER verbs to describe the video clips of motion events, whereas Greek speakers preferred PATH verbs. These results showed cross-linguistic differences between English-and Greek speakers. A comparison of young children who were acquiring English and Korean (Choi \& Bowerman, 1991) determined that children's construction of early spatial semantic categories is language-specific, and suggested that children are guided in the lexicalization patterns of motion events by the language to which they are exposed from the beginning.

Talmy (2000) assured that PATH is considered to be the "core-schema" of a motion event. In child language acquisition, some studies proposed universal verb construal, which holds that children initially show similar conceptualization patterns regardless of their native language. As knowledge of their native languages increases, the universal set of event components for the verb system becomes language specific. Children's default verb interpretation for a novel verb is to encode the PATH with significant preference over the MANNER of motion (Allen et al., 2007; Gentner, 2003; Maguire \& Dove, 2008). Several naturalistic observations also reported that children's utterances include more PATH verbs or PATH components than MANNER verbs or MANNER components (Allen et al, 2007; Choi \& Bowerman, 1991; Goldin-Meadow \& Zheng, 1998). Interestingly, however, research findings incompatible with PATH as "core-schema" of a motion event were observed. Oh (2003) examined L1 English children (mean age 3:8) and adults and L1 Korean children (mean age 3:65) and adults to elicit verbal descriptions of video clips containing motion events. Oh's (2003) results were contradictory to previous literature in that both groups of young children produced a high tendency to describe motion events in terms of MANNER only and to ignore PATH. Even though children in both groups expressed MANNER of motion more than PATH in their description, the elaboration of MANNER verbs were limited mostly to walk and run verbs. Adults, on the contrary, expressed MANNER motion with further elaboration in half of descriptions by Korean-speaking adults and even more descriptions by English-speaking adults. 
Research on L2 learners' or bilinguals' production of motion events has shown diverse results about the possibility of switch to canonical L2 type of behavior and of $\mathrm{L} 1$ retention in thinking for speaking.

The thinking for speaking proposal implies that thought can bring about languagespecific patterns during online processing only when language is involved, but not when language (i.e., speaking) is not involved. In this respect, Lai et al. (2014) in a forced similarity judgment test found that the classification of motion events by Spanish-English bilinguals was affected by the language (either Spanish or English) that was used to verbally encode the motion event. Hohenstein (2006) examined early and late L1 Spanish-L2 English bilinguals who watched dynamic videos of motion events and were asked to describe the action. The bilinguals used more MANNER verbs in English and PATH verbs in Spanish, which confirms the language-specific lexicalization patterns between English and Spanish in motion encoding.

Cross-linguistic differences have been observed in different L1s, whereas L1 retention in thinking for speaking has been observed in L2. For instance, in a verbal description task, English and French monolinguals clearly show cross-linguistic differences that are typical typological patterns expected from MANNER-oriented language (English) and PATH-oriented language (French); however, English speakers of L2 French showed a trace of thinking for speaking pattern of English (L1) by providing a MANNER verb separately from a PATH verb (Hendriks \& Hickmann, 2011). The interesting interpretation about L1 retention is that L2 leaners escape from the L2 mode to L1 mode to solve problems in organizing information in L2 in order to increase the efficiency of communication. Learners will eventually switch off the L1 mode of thinking for speaking to become entirely native-like.

Using a new mode of behavior, Choi and Lantolf (2008) also investigated the L1 retention effect in thinking for speaking in gesture. Using an animated cartoon story by advanced L2 speakers of Korean (L1 English) and L2 speakers of English (L1 Korean), Choi and Lantolf (2008) found that the typological difference between English and Korean prohibits L2 speakers from shifting toward L2 thinking for speaking patterns, even though their level of proficiency in L2 was highly advanced. L1 thinking for speaking patterns were retained by these advanced L2 learners.

However, the influence of L1 thinking for speaking may not be present in advanced L2 learners. For instance, Cadierno and Ruiz (2006) examined how MANNER and PATH of motion could be expressed depending on whether L1/L2 
are MANNER/PATH or PATH/PATH. When asked to write a narration to describe the 'frog story' (Slobin, 1996; 2000), a group of Danish (MANNER-oriented language) learners of Spanish (PATH-oriented) did not produce MANNER of motion to a greater extent than did a group of Italian (PATH-oriented language) learners of Spanish. Moreover, Danish learner group expressed more PATH of motion than the Italian learner group and the Spanish control group. These results "seem to support the view of a rather limited role of the L1 thinking for speaking patterns in advanced adult language learners (p. 207)." The authors hypothesized that the influence of L1 thinking for speaking might be stronger during the initial and intermediate stages of acquisition, but gradually disappears as the proficiency of the learner increases.

In contrast, L2 can influence L1 in descriptions of motion events. For instance, Brown and Gullberg (2013) found that L2 affected L1 syntactic clausal packaging of MANNER and PATH by Japanese learners of L2 English. English uses a MANNER main verb plus a PATH satellite in a single clause, whereas Japanese uses multiple main verbs, e.g., MANNER main verbs plus PATH main verbs, and can therefore compose multiple clauses. Aveledo and Athanasopoulos (2016) also found L2 influence on L1 motion event encoding by early bilingual L1 Spanish children (aged 5;00-9;00) learning L2 English who used more MANNER verbs and fewer PATH verbs in their L1 as a result of the influence of L2.

\subsection{Research on non-linguistic perception of motion}

Considering cross-linguistic differences between MANNER-oriented languages and PATH-oriented languages in encoding motion events, a reasonable question is whether the non-linguistic behavior of speakers from these language groups differs in the same way as the linguistic patterns of their languages. Here, we examine the interplay between lexicalization of motion and non-linguistic cognition during thinking without speaking.

In the recognition task (a task in which participants are asked to decide whether they saw a particular stimulus during the previous experiment), Malt, Sloman and Gennari (2003), Papafragou, Massey and Gleitman (2002) and Loucks and Pederson (2011) found no language effects, even when the classification of events was preceded by verbalization of the stimuli. For instance, Malt et al. (2003) asked L1 Spanish and L1 English speakers to watch short films portraying motion events. Participants were asked to point to two out of three pictures of actions that seemed most similar 
to each other. No effect of language-specific lexicalization strategy on visual memory recognition was found in either the English or Spanish speakers, which could suggest that linguistic and non-linguistic behaviors are not dependent on each other in a strong sense of the linguistic relativity hypothesis.

Papafragou and colleagues examined cross-linguistic differences in attending to dynamic motion event using eye-tracking methodology. Papafragou et al. (2008) and Trueswell and Papafragou (2010) found that English and Greek adult native speakers displayed different patterns of visual attention, preferring periphery encoding strategy in each language: English native speakers spent more time inspecting the PATH end point rather than the MANNER of motion, whereas Greek native speakers displayed toward the opposite pattern. Trueswell and Papafragou (2010) called this tendency reverse-Whorfian effect, to which we will return in discussion.

Papafragou and Selimis (2010) tested the possible effect of language on event categorization by examining English-and Greek-speaking adults and five-year-old children. In a similarity judgment task, language specific effects on perceiving the motion events were observed when the experiment prompt included linguistic instructions (e.g., Look the $\mathrm{X}$ is doing something!). However, when the prompt was given without linguistic intrusion (e.g., Look!), similar categorization of events occurred in non-linguistic conditions regardless of the participants' native language. They concluded that there are no cross-linguistic differences in the situations that involve no language use and that the conceptual representation is universal.

To investigate cross-linguistic differences in motion event perception in bilingual speakers, Czechowska and Ewert (2011) examined whether the non-linguistic behavior of speakers from English and Polish differs in line with the linguistic lexicalization patterns of their languages. Although both English and Polish belong to the same group of Satellite-framed languages that encode MANNER of motion more saliently than its PATH, English and Polish have crucial differences in motion lexicalization in that speakers of English will pay more attention to PATH of motion in comparison to speakers of Polish. Czechowska and Ewert (2011) asked L1 Polish L2 English bilinguals to rate the similarity between pictures and found that bilinguals switched toward L2-based conceptual representation, paying more attention to PATH of motion, which was consistent with English monolinguals' behavior. Czechowska and Ewert (2011) also found that the non-linguistic perception was affected by L2 proficiency, quality and quantity of the exposure to L2. 


\section{The Present Study}

In the present study, L1 Korean L2 English learners and L1 English speakers were asked to rate the similarity of motion events and to describe motion events in short animations that were displayed on a computer monitor. The experiment was divided into three blocks (Figure 1). In the first block (0L), no verbal description was required: participants were asked to view two motion events and to rate the similarity between them. In the second (1L) block, participants were required to produce verbal descriptions of the events in their L1. In the third block (2L), all speakers were required to describe the motions in English; i.e., either as $\mathrm{L} 1$ or as $\mathrm{L} 2$.

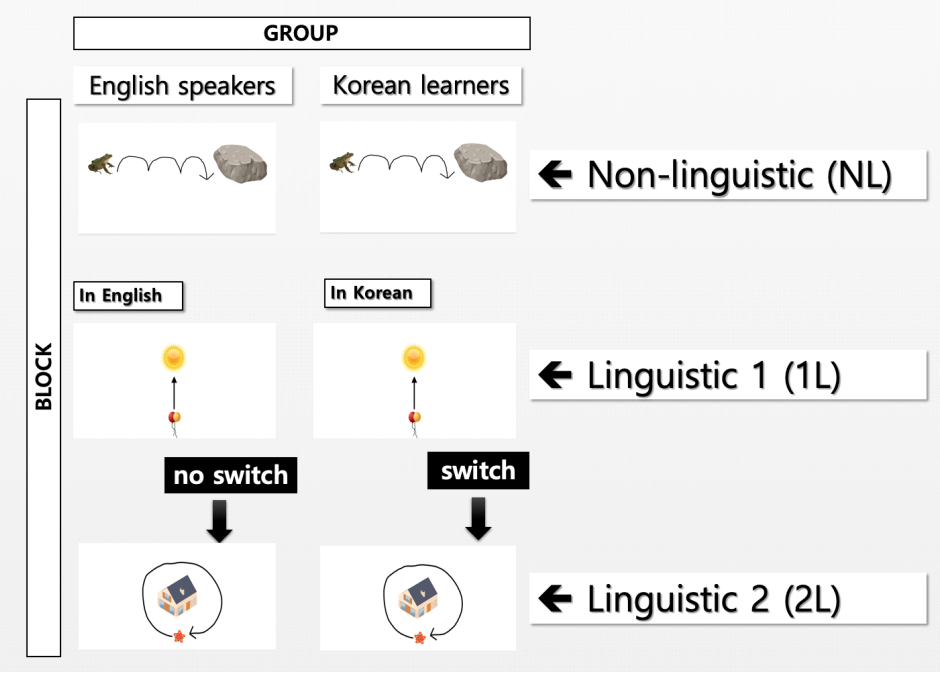

Figure 1. Schematic representation of animation stimulus for verbal description in $1 \mathrm{~L} / 2 \mathrm{~L}$ block.

\subsection{Research questions}

This experiment aimed to provide data that would bear on the following research questions and predictions.

1) Do L1 English and Korean speakers differ in the verbal descriptions of motion events in the linguistic $1 \mathrm{~L}$ block? 
2) Do L1 Korean L2 English learners switch to the MANNER-oriented description type that is canonical for English in the linguistic 2L block?

3) If linguistic switch occurs in the 2L block, do L1 Korean L2 English learners experience cognitive restructuring towards L2-based conceptual representation of motion events by showing similar conceptualization patterns to L1 English speakers in the non-linguistic 0L block?

\subsection{Research hypotheses}

\subsubsection{Hypothesis 1 (1L Block)}

At the most general level, because of the cross-linguistic difference between English and Korean lexicalization patterns of motion events, I predict that L1 English and Korean speakers would differ in their verbal description behavior in the linguistic $1 \mathrm{~L}$ block: Korean speakers should overwhelmingly favor PATH-oriented descriptions, whereas English speakers should generally produce MANNER-oriented descriptions. This prediction is consistent with thinking for speaking (Slobin, 1996; 2004), which argues that language may influence conceptualization of experience when this experience is linguistically mediated. In the $1 \mathrm{~L}$ block linguistic condition, speakers think about the reality in order to encode it for speech.

\subsubsection{Hypothesis 2 (2L Block)}

When L1 Korean L2 English learners are required to switch to their L2 (English) in the $2 \mathrm{~L}$ block, they might either simply switch to the MANNER-oriented description type that is canonical for English, or they might transfer their native Korean PATH-oriented descriptions into English or exhibit some variety of mixed behavior.

\subsubsection{Hypothesis 3 (OL Block)}

The non-linguistic condition, in which language use is not involved in event categorization, is crucial to the question of the present study: whether conceptual restructuring can occur in non-linguistic condition when the linguistic switch occurred in L2 description of motion events. Two possibilities can be predicted. One possibility is that cognitive restructuring would occur: Korean speakers will shift towards L2-based conceptual representation, being more sensitive to the SAME 
MANNER alternate in the non-linguistic 0L block.

The other possibility is that cognitive restructuring may fail to occur. Although linguistic switch to L2 English canonical description type occurred in the linguistic 2L block, Korean speakers will still be more sensitive to the SAME PATH alternate that is L1-type conceptual representation in the non-linguistic 0L block.

\section{Method}

\subsection{Participants}

The participants in this study were 20 Korean learners of English (3 females, 17 males) who were undergraduate students (mean age 25, range: 20-24) and 13 English native speakers who were either instructors or exchange students (mean age 35, ranged: 21-45) at a Korean university. None of the Korean learners of English had lived in English-speaking countries for more than three months. Based on the criteria of an intramural speaking and writing test and curriculum system developed by the university, participants in this study were categorized into advanced group.

\subsection{Materials}

Test items were 16 sets of animations; each set consisted of three related animations. The total number of animations that participants saw was 48. Each set consisted of an Original event and two variant events (Figure 2). The Original events involved entities (persons, animals, or objects) moving along a PATH (e.g., to, from, under) in a certain MANNER (e.g., the leaf spinning away from a tree).

All test stimuli involved change-of-state events; each of the variants depicted a specific change to the Original event (Figure 2a). For example, in the SAME MANNER variant (Figure $2 b$ ), the PATH was changed, but the MANNER remained the same (the leaf spinning down from a tree). In the SAME PATH variant (Figure 2c), the MANNER of movement was changed, but PATH was kept the same (the leaf blown away from a tree). Half of the animation sets involved animate agents, and the other half involved inanimate agents. There were 2 sets of practice animations that did not involve pure motion events in which the moving character presented spatial relations. Also, 12 filler items that were designed for another study involving animations were used. 


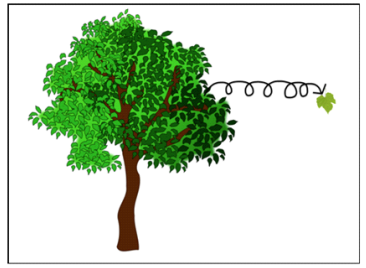

(a) Original

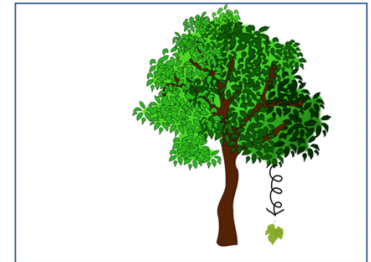

(b) SAME MANNER

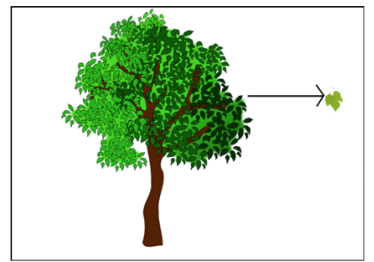

(c) SAME PATE

Figure 2. Sample stimuli. From left to right: Original event (leaf spinning away from a tree), SAME MANNER variant (leaf spinning down from a tree), SAME PATH variant (leaf blown away from a tree).

\subsection{Procedure}

Participants were asked to watch the Original animation presented on a computer screen, remembering the animation, then press a button when they were ready to see a new animation, which caused the Original baseline animation to disappear from the screen. Then, they were asked to rate the similarity between the next animation (e.g., SAME MANNER variant) to the Original animation. A 7-point scale was used, 1 being least similar and 7 being most similar. Then, the participant watched the same Original baseline animation again, remembering it, then, press the button to play the second variant animation (e.g., SAME PATH variant) and rate its similarity to the Original. The order of each variant presented after the Original baseline stimuli was counter-balanced.

After the similarity rating task in the (non-linguistic) 0L block, participants were shown and asked to verbally describe each of the Original animations. Korean L2 learners verbally described the motion events in Korean during the 1L block and in English during the 2L block by switching from Korean to English. However, English L1 speakers used English in both blocks without switching language, so they repeated the same session (Figure 1). All utterances by participants were automatically recorded by a computer and transcribed later for analyses. To minimize the language effect on perception found in previous studies (Gennari et al., 2002; Papafragou \& Selimis, 2010), where participants linguistically encode the stimuli before they respond to a non-linguistic task, (non-linguistic) $0 \mathrm{~L}$ block preceded the $1 \mathrm{~L}$ and the $2 \mathrm{~L}$ block in the present experiments. The experiment took approximately $30 \mathrm{~min}$ per student. 


\subsection{Coding}

Each participant produced 16 utterances that depicted the motion events in the animations. For each utterance, the main verb was coded as MANNER verb, PATH verb or Other verb. The example sentence structures of verbal description in Korean (Table 1) and English (Table 2) are provided. I counted the total number of MANNER verbs and total number of PATH verbs for the utterances of each participant and calculated the average scores to determine his or her lexicalization patterns of motion events.

Table 1. Example sentences in Korean (as described by participants)

\begin{tabular}{ll}
\hline \multicolumn{1}{c}{ Sentence structure } & \multicolumn{1}{c}{ Example sentence } \\
\hline \hline Path Verbs (PVs) & 떨어지고 있습니다. \\
PV only & 낙하산 타고 떨어지고 있습니다. \\
PV + Manner modifier & 썰매를 탄 남자가 나무를 향해 떨어지고 있습니다. \\
PV + Path modifier & 한 여자가 비행기 위에 메달려 터널 안으로 진입하고 있다. \\
PV + Manner modifier + Path modifier & 여자가 하늘에서 나무쪽으로 풍선을 메고 떨어지고 있다. \\
PV + Path modifier + Manner Modifier & \\
\hline Manner Verbs (MVs) & 한 남성이 이동하고 있습니다. \\
MV only & 사람이 요트를 타고 이동하고 있어요. \\
MV + Manner modifier & 나무 옆으로 착륙하고 있습니다. \\
MV + Path modifier & 남자가 요트를 타고 결승점을 향해 이동하였습니다. \\
MV + Manner modifier + Path modifier & 어떤 남자가 왼쪽 건물쪽으로 부스터를 달고 날아가고 있어요. \\
MV + Path modifier + Manner Modifier & 테러범이다. \\
\hline Other Verbs &
\end{tabular}

Table 2. Example sentences in English (as described by participants)

\begin{tabular}{ll}
\hline \multicolumn{1}{c}{ Sentence structure } & \multicolumn{1}{c}{ Example sentence } \\
\hline \hline Path Verbs (PVs) & The man enter the house. \\
PV only & A boy passes the cave with his skateboard. \\
PV + Manner modifier & A car is going to the tree. \\
PV + Path modifier & A boy with the rocket is going up to a building. \\
PV + Manner modifier + Path modifier & A man is falling from airplane with a. parachute. \\
PV + Path modifier + Manner Modifier & \\
\hline Manner Verbs (MVs) & A man is moving. \\
MV only & She is landing with her parachute. \\
MV + Manner modifier & A ball rolled toward the tree. \\
MV + Path modifier & A gramma is flying with an airplane to the tunnel. \\
MV + Manner modifier + Path modifier & A girl is sliding to the bench in a car. \\
MV + Path modifier + Manner Modifier & There is house. \\
\hline Other Verbs &
\end{tabular}




\section{Results}

\subsection{Linguistic encoding (Verbal description task)}

In the 1L block, L1 English speakers produced more MANNER verbs $($ Mean = $0.76, \mathrm{SD}=0.23$ ) than PATH verbs (Mean $=0.17, \mathrm{SD}=0.22$ ), whereas all Korean L2 learners produced more PATH verbs (Mean $=0.76, \mathrm{SD}=0.19$ ) than MANNER verbs (Mean $=0.23, \mathrm{SD}=0.19$ ). A two-way ANOVA was conducted with Language Group (Korean vs. English) and Verb (PATH vs. MANNER) as independent variables, and mean score of produced verbs as a dependent variable. The main effect of Language Group was not significant $(\mathrm{F}(1.30)=0.139, p>0.05)$; i.e., the difference in the mean score of verbs between the two language groups was not significant. The main effect of Verb was significant $(\mathrm{F}(1.30)=34.596, p<0.05$. This suggests that the difference between the production of PATH verb and MANNER verb was statistically significant. The interaction between Language Group and Verb was significant $(\mathrm{F}(1.30)=155.076, p<0.05)$. The result suggests that Korean speakers preferred PATH verbs, whereas English speakers preferred MANNER verbs. This result confirms the lexicalization patterns of motion events predicted from the language-specific patterns in that Korean is a PATH-oriented language and English is a MANNER-oriented language.

In the 2L block, the preference of the L1 English speakers was unchanged (Mean $=0.73, \mathrm{SD}=0.27$ for MANNER verbs; Mean $=0.24, \mathrm{SD}=0.28$ for PATH verbs), but the Korean L2 learners produced more MANNER verbs $($ Mean $=0.76, \mathrm{SD}=$ 0.20 ) than PATH verbs (Mean $=0.21, \mathrm{SD}=0.18$ ), in contrary to the $1 \mathrm{~L}$ block. A two-way ANOVA was conducted with Language (Korean vs. English) and Verb (PATH vs. MANNER) as independent variables, and mean score of produced verbs as a dependent variable. The main effect of Language was significant $(F(1,31)=$ $15.49, p<0.05$ ); the difference in the mean score of verbs between the two language groups was significant. The main effect of Verb was significant $(\mathrm{F}(1.31)=228.798$, $p<0.05$. This suggests that the mean difference between the production of PATH verb and MANNER verb was statistically significant. The interaction between Language and Verb was significant $(\mathrm{F}(1.31)=35.160, p<0.05)$. This suggests that both Korean and English speakers produced more MANNER verbs than PATH verbs in the 2L block, but the tendency is stronger for English speakers. These results suggest that Korean learners could switch to the L2 (English) type of encoding the motion events by using more MANNER verbs than PATH verbs as English L1 speakers do (Table 3). 
Table 3. Average proportion of MANNER verbs and PATH verbs in each language block (SD = Standard Deviation)

\begin{tabular}{llll}
\hline & Group & MANNER (SD) & PATH (SD) \\
\hline \hline $1 \mathrm{~L}$ & & & \\
English & L1 English & $0.76(0.23)$ & $0.17(0.22)$ \\
Korean & Korean L2 & $0.23(0.19)$ & $0.76(0.19)$ \\
\hline 2L & & & \\
English & L1 English & $0.73(0.27)$ & $0.24(0.28)$ \\
English & Korean L2 & $0.76(0.20)$ & $0.21(0.18)$ \\
\hline
\end{tabular}

\subsection{Non-linguistic perception}

With the Original animation as the basis for comparison, both groups of speakers rated SAME PATH variants to be more similar than SAME MANNER variants (Table 4), but the tendency was stronger for Korean L2 learners than for L1 English speakers.

Table 4. Mean scores of similarity ratings by L1 Korean L2 English learners and L1 English speakers

\begin{tabular}{ccc}
\hline & \multicolumn{2}{c}{ Language group } \\
\cline { 2 - 3 } Variant & $\begin{array}{c}\text { L1 Korean L2 English } \\
(\mathrm{n}=20)\end{array}$ & $\begin{array}{c}\text { L1 English speakers } \\
(\mathrm{n}=13)\end{array}$ \\
\hline \hline SAME MANNER & $4.05(1.00)$ & $3.87(1.02)$ \\
SAME PATH & $4.60(0.75)$ & $4.07(1.11)$ \\
\hline
\end{tabular}

A two-way analysis of variance was conducted with Language Group (Korean vs. English) and Variant (SAME MANNER vs. SAME PATH) as independent variables, and similarity rating score as a dependent variable. The main effect of Language Group was not significant $(\mathrm{F}(1.31)=1.237, p>0.05)$; i.e., the mean difference in similarity scores between L1 English speakers and Korean L2 learners was not significant. Both L1 and L2 groups showed similar behavior in the perception of motion events. The main effect of Variant was significant; SAME PATH variants were perceived more similar to the baseline Original stimuli with higher similarity scores than SAME MANNER variants were and the mean difference was significant $(\mathrm{F}(1.31)=9.393, p<0.05)$. The interaction between Language Group and Variant was not significant $(\mathrm{F}(1.31)=2.014, p>0.05)$. The results suggest that both L1 English speakers and Korean L2 learners focused more on PATH of motion than 
on MANNER of motion in the non-linguistic OL condition.

\section{Discussion}

The first research question asked whether native English speakers and Korean learners of English differed in their verbal description of motion events in the $1 \mathrm{~L}$ block.

Research hypothesis 1 was supported. Results of verbal description in the 1L block showed language specific differences in lexicalization patterns between English and Korean. L1 English speakers produced more MANNER verbs than PATH verbs in their L1 English when they described motion events. L1 Korean speakers produced more PATH verbs than MANNER verbs in their L1 Korean. The results confirmed Talmy's $(1985,2000)$ typological differences instantiated in Slobin's (1996) thinking for speaking in encoding motion events that explain that language specific treatment of lexicalization differs in English (MANNER-oriented language) and Korean (PATH-oriented language).

Language-specific lexicalization patterns of motion events in their native languages in the 1L block conform to the Sapir-Whorf hypothesis: "“..users of markedly different grammars are pointed by their grammars towards different types of observations and different evaluations of externally similar acts of observation, and hence are not equivalent as observers but must arrive at somewhat different views of the world. (Whorf, [1940] 2012, pp 282-283)". This paragraph, conceivably one of the most cited in the history of linguistics, is the basis of the argument about linguistic determinism derived from "the seductive force of habit" (Leavitt, 2011, p. 146).

The second research question was whether Korean learners of English could switch to their L2 (English) type when they were asked to describe motion events in English in the 2L block. Korean learners used more MANNER verbs than PATH verbs in their L2 (English), whereas they used more PATH verbs than MANNER verbs in their L1. This difference suggests a switch to the patterns of L2 thinking for speaking. Based on this result, research hypothesis 2 was supported.

The shift when using L2 suggests that the bilingual processing of the L2 learners is like that of the two monolinguals (Korean-like in 1L block and English-like in 2L block). This separate processing for each language is in line with the theory of monolingual mode (Grosjean, 2001). 
Although it was predicted in the research hypothesis that Korean L2 learners might engage in a direct translation, transferring their native Korean PATH-oriented descriptions into English, or might exhibit some variety of mixed behavior, the results of verbal prediction in the $2 \mathrm{~L}$ block did not show any clear tendency of L1 transfer. This result suggests that the Korean L2 learners in this study showed limited influence of L1 thinking for speaking patterns when they speak L2. In addition, the bidirectional transfer observed in L1 Spanish-L2 English bilingual adults (Hohenstein, 2006) was not observed in the present study, although bidirectional transfer of motion encoding patterns (i.e., L1àL2 and L2àL1) can be expected in bilingual speakers whose L1 and L2 encode motion differently.

If the structure of a language determines a native speaker's perception and categorization of experience, i.e., if language affects the way native speakers of the language perceive the world, will learning an additional language could result in conceptual changes?

The first possibility is that learning another language does not have any conceptual effects; new linguistic items - whether lexical labels or grammatical rules - are learned, and communication with users of another language is achieved, without any conceptual change. It is possible to learn to communicate in another language without a change in one's concepts. In this case, if bilinguals differ from monolinguals, it is only in how they think about reality in order to encode it for speech, a.k.a. 'thinking-for-speaking' (Slobin, 1996), not in how they think.

If this hypothesis is true, the third research question asked whether L2 learners would shift towards L2-based conceptual representations, and pay more attention to MANNER of motion in the non-linguistic 0L block. The results showed that they did not: L1 Korean L2 English learners were more sensitive to PATH of motion than to MANNER of motion in conceptualization. Although linguistic switch to $\mathrm{L} 2$ did occur in the $2 \mathrm{~L}$ block, the cognitive restructuring did not occur in the $0 \mathrm{~L}$ block for these L2 learners. Learning an additional language did not result in conceptual changes when language was not used. Interestingly, contrary to the predictions, L1 English speakers did not pay more attention to MANNER of motion than to PATH; rather, they paid more attention to PATH than to MANNER as Korean L2 learners did. I will return to this point below.

Linguistic determinism, the strong version of the Sapir-Whorf hypothesis, holds that differences of language will be associated with differences of thought; i.e., that language and thought covary. Determinism goes beyond this assertion to require that the prior existence of some language pattern is either necessary or sufficient 
to produce some thought pattern. However, results of the non-linguistic condition of the present study do not confirm the strong version of Sapir-Whorf hypothesis: Language-specific difference between Korean and English was not observed when language was not involved in the conceptualization.

To explain the similar behavior patterns in L1 and L2 that focused more on the PATH of motion in the 0L block, two accounts can be provided. First, PATH can be considered to be the "core-schema" of a motion event, as Talmy (2000) asserted. As mentioned in the previous section, there are many L1 studies that show that children from various L1 backgrounds produced PATH verbs more often than MANNER verbs (e.g., Goldin-Meadow \& Zheng, 1998; Choi \& Bowerman, 1991). Therefore, PATH of motion may be universal property in encoding motion events. Alternatively, the English speakers demonstrated the reverse-Whorfian effect: they preferred a periphery encoding strategy in English, i.e., PATH of motion, as was observed by English speakers in Papafragou et al. (2008) and Trueswell and Papafragou (2010). It is plausible that the length of stay in Korea of the English speakers in the present study and their subsequent exposure to L2 (Korean) input, although they are using English only in Korea, might have affected their conceptual restructuring to be more sensitive to PATH of motion. Further research is required with L1 English speakers with different length of stay in Korea to account for the reverse-Whorfian effect by them.

\section{Conclusion}

This study attempted to fill a gap in the current literature by examining both lexical and syntactic representation with regard to description and perception of motion events in the acquisition and processing of L2 learners in an EFL context. The approach probed whether conceptual restructuring occurs in a non-linguistic condition during linguistic switch to L2-type description. L2 learners did now show cognitive restructuring when language was not involved, even though language specific lexicalization patterns were observed in linguistic conditions and switch to L2 canonical type of description (2L block). Cognitive restructuring failed to occur by L2 learners when language was not involved. This study suggests that linguistic switch did not evoke subsequent cognitive change in L2 acquisition and processing. 


\section{References}

Allen, S., Özyürek, A., Kita, S., Brown, A., Furman, R., Ishizuka, T., \& Fujii, M. (2007). Language-specific and universal influences in children's syntactic packaging of manner and path: A comparison of English, Japanese, and Turkish. Cognition, 102(1), 16-48.

Athanasopoulos, P., \& Bylund, E. (2013). Does grammatical aspect affect motion event cognition? A cross-linguistic comparison of English and Swedish speakers. Cognitive Science, 37, 286-309.

Aveledo, F., \& Athanasopoulos, P. (2016). Second language influence on first language motion event encoding and categorization in Spanish-speaking children learning L2 English. International Journal of Bilingualism, 20(4), 403-420.

Bassetti, Benedetta, and Vivian Cook. (2011). Relating language and cognition: The second language user. In V. Cook \& B. Bassetti (Eds.), Language and bilingual cognition (pp. 143-190). New York, NY: Psychology Press.

Berman, L., \& Slobin, D. I. (1994). Relating events in narrative: A cross-linguistic developmental study. Hillsdale, NJ: Lawrence Erlbaum Associates.

Brown, A., \& Gullberg, M. (2013). L1-L2 convergence in clausal packaging in Japanese and English. Bilingualism: Language and Cognition, 16(3), 477-494.

Brown, R. W., \& Lenneberg, E. H. (1954). A study in language and cognition. The Journal of Abnormal and Social Psychology, 49(3), p.454.

Bylund, E. (2009). Effects of age of L2 acquisition on L1 event conceptualization patterns. Bilingualism: Language and Cognition, 12(3), 305-322.

Bylund, E., \& Athanasopoulos, P. (2014). Language and thought in a multilingual context: The case of isiXhosa. Bilingualism: Language and Cognition, 17(2), 431-441.

Cadierno, T., \& Ruiz, L. (2006). Motion events in Spanish L2 acquisition. Annual Review of Cognitive Linguistics 4, 183-216.

Choi, S., \& Bowerman, M. (1991). Learning to express motion events in English and Korean: The influence of language-specific lexicalization patterns. Cognition, 41, 83-121.

Choi, S., \& Lantolf, J. P. (2008). Representation and embodiment of meaning in L2 communication: Motion events in the speech and gesture of advanced L2 Korean and L2 English speakers. Studies in Second Language Acquisition, 30(2), 191-224.

Czechowska, N., \& Ewert, A. (2011). Perception of motion by Polish-English bilinguals. In V. Cook \& B. Bassetti (Eds.), Language and bilingual cognition (pp. 287-314). New York, NY: Psychology Press.

Gentner, D. (2003). Why we're so smart. In D. Gentner \& S. Goldin- Meadow (Eds.), Language in mind (pp. 195-236). Cambridge, MA: The MIT Press.

Goldin-Meadow, S., \& Zheng, M. (1998). Thought before language: The expression of motion events prior to the impact of a conventional language model. Carruthers and Boucher, 26-54. Grosjean, F. (2001). The bilingual's language modes. In J. Nicol (Ed.), One mind, two 
languages: Bilingual language processing (pp.1-22). Oxford: Blackwell.

Hendriks, H., \& Hickmann, M. (2011). Expressing voluntary motion in a second language: English learners of French. In V. Cook \& B. Bassetti (Eds.), Language and bilingual cognition (pp. 315-339). New York, NY: Psychology Press.

Hohenstein, J. (2006). Is he floating across or crossing afloat? Cross- influence of L1 and L2 in Spanish-English bilingual adults. Bilingualism: Language and Cognition, 9, 249-261. Lai, V. T., Rodriguez, G. G., \& Narasimhan, B. (2014). Thinking-for-speaking in early and late bilinguals. Bilingualism: Language and Cognition, 17(1), 139-152.

Leavitt, J. (2011). Linguistic relativities: Language diversity and modern thought. Cambridge, UK: Cambridge University Press.

Lucy, J. A. (1992). Language diversity and thought: A reformulation of the linguistic relativity hypothesis. Cambridge, UK: Cambridge University Press.

Maguire, M. J., \& Dove, G. O. (2008). Speaking of events: What event language can tell us about event representations and their development. In T. F. Shipley \& J. Zacks (Eds.), Understanding events: From perception to action (pp. 193-220). New York, NY: Oxford University Press.

Malt, B. C., Sloman, S. A., \& Gennari, S. P. (2003). Universality and language specificity in object naming. Journal of Memory and Language, 49(1), 20-42.

Oh, K.-J. (2003). Manner and Path in motion event descriptions in English and Korean. In B. Beachley, A. Brown \& F. Conlin (Eds.), Proceedings of the 27th Annual Boston University Conference on Language Development (pp. 580-590). Somerville, MA: Cascadilla Press.

Papafragou, A., \& S. Selimis. (2010). Event categorisation and language: A cross-linguistic study of motion. Language and Cognitive Processes, 25(2), 224-260.

Papafragou, A., Hulbert, J., \& Trueswell, J. (2008). Does language guide event perception? Evidence from eye movements. Cognition, 108(1), 155-184.

Papafragou, A., Massey, C., \& Gleitman, L. (2002). Shake, rattle,'n'roll: The representation of motion in language and cognition. Cognition, 84(2), 189-219.

Slobin, D. (1996). From "thought and language" to "thinking for speaking". Rethinking Linguistic Relativity, 17, 70-96.

Slobin, D. (2000). Verbalized events: A dynamic approach to linguistic relativity and determinism. In S. Niermeier \& R. Dirven (Eds.), Evidence for linguistic relativity (pp. 107-138). Amsterdam: John Benjamins.

Slobin, D. (2004). The many ways to search for a frog. In S. Strömqvist \& L. Verhoeven (Eds.), Relating Events in Narrative. Vol, 2, Typological and contextual perspectives (pp. 219-257). Mahwah, NJ: Lawrence Erlbaum Associates.

Swoyer, C. (2011). How does language affect thought? In V. Cook \& B. Bassetti (Eds.), Language and bilingual cognition (pp. 3-22). New York, NY: Psychology Press.

Talmy, L. (1985). Lexicalization patterns: Semantic structure in lexical forms. In T. Shopen (Ed.), Language typology and lexical description: vol.3. Grammatical categories and the lexicon (pp. 57-149). Cambridge: Cambridge University Press. 
Talmy, L. (2000). Toward a cognitive semantics: vol. II: Typology and process in concept structuring. Cambridge, MA: MIT Press.

Trueswell, J, \& A. Papafragou (2010). Perceiving and remembering events cross-linguistically:

Evidence from dual-task paradigms. Journal of Memory and Language, 63, 64-82.

Whorf, Benjamin (2012). Language, thought and reality: Selected writings of Benjamin Lee Whorf (2nd ed). Eds by J. B. Carroll, S. C Levinson \& P. Lee. Cambridge, MA: MIT Press (Original work published 1940).

Soo-Ok Kweon

Professor

Division of Humanities \& Social Sciences, POSTECH

77 Chengam-ro, Nam-gu Pohang, Kyungpook 37673, Korea

E-mail: soook@postech.ac.kr

Received: October 12, 2019

Revised version received: November 7, 2019

Accepted: December 16, 2019 